\title{
Post-Marketing Benefit-Risk Assessment of Rotavirus Vaccination in Japan: A Simulation and Modelling Analysis
}

\author{
Edouard Ledent ${ }^{1} \cdot$ Alfons Lieftucht $^{2} \cdot$ Hubert Buyse $^{3} \cdot$ Keiji Sugiyama $^{4}$. \\ Michael Mckenna $^{3,6} \cdot$ Katsiaryna Holl $^{5}$
}

Published online: 9 January 2016

(c) The Author(s) 2016. This article is published with open access at Springerlink.com

\begin{abstract}
Introduction Rotarix ${ }^{\mathrm{TM}}$, GSK's live attenuated rotavirus vaccine, was introduced in Japan in 2011. A recent trend in reduction of rotavirus gastroenteritis (RVGE) due to this vaccine was described. However, an observed/expected analysis showed a temporal association with intussusception within 7 days post dose 1 .

Objective In this paper, we compare the benefit and risk of vaccination side-by-side in a benefit-risk analysis.

Methods The number of vaccine-preventable RVGE-associated hospitalizations and deaths (benefit) and intussusception-associated hospitalizations and deaths (risk) following two doses of Rotarix ${ }^{\mathrm{TM}}$ in Japan was compared using simulations. Source data included peer-reviewed clinical and epidemiological publications, Japanese governmental statistics (Statistics Bureau, Ministry of Internal Affairs and Communications), and market survey data.
\end{abstract}

E. Ledent and A. Lieftucht contributed equally.

Electronic supplementary material The online version of this article (doi:10.1007/s40264-015-0376-7) contains supplementary material, which is available to authorized users.

Edouard Ledent

edouard.y.ledent@gsk.com

1 Clinical Statistics, GSK Vaccines, Rixensart, Belgium

2 Chief Medical Office, GSK UK Ltd, Uxbridge, UK

3 Safety Department, GSK Vaccines, Wavre, Belgium

4 Japan Vaccine Co., Ltd., Tokyo, Japan

5 Health Economics Department, GSK Vaccines, Wavre, Belgium

6 Present Address: Otsuka Europe Development and Commercialisation Ltd, Wexham, UK
Results For a birth cohort of 1 million vaccinated Japanese children followed for 5 years, the benefit-risk analysis suggested that the vaccine would prevent $\sim 17,900$ hospitalizations and $\sim 6.3$ deaths associated with RVGE. At the same time, vaccination would be associated with about $\sim 50$ intussusception hospitalizations and $\sim 0.017$ intussusception deaths. Therefore, for every intussusception hospitalization caused by vaccination and for one intussusception-associated death, 350 (95\% CI 69-2510) RVGE-associated hospitalizations and 366 (95\% CI 59-3271) RVGE-associated deaths are prevented, respectively, by vaccination.

Conclusions The benefit-risk balance for Rotarix ${ }^{\mathrm{TM}}$ is favorable in Japan. From a public health perspective, the benefits in terms of prevented RVGE hospitalizations and deaths for the vaccinated population far exceed the estimated risks due to intussusception.

\section{Key Points}

Following the introduction of Rotarix ${ }^{\mathrm{TM}}$ in Japan in 2011, a reduction in rotavirus gastroenteritis (RVGE) was observed.

Other studies have shown a transient increase in the incidence of intussusception in the immediate postvaccination period.

Our benefit-risk analysis indicates that, given the assumptions made, the numbers of RVGE hospitalizations and deaths prevented by vaccination are about 350 times higher than those potentially caused by intussusception. 


\section{Introduction}

Rotavirus is the leading cause of severe gastroenteritis in children under 5 years of age worldwide [1]. Although rotavirus gastroenteritis (RVGE)-associated mortality is very low in developed countries [2], RVGE accounts for a large number of hospitalizations [3, 4]. In Japan, the burden associated with RVGE was shown to be substantial [5-10], highlighting the need for vaccination against rotavirus infection.

A live attenuated rotavirus vaccine (Rotarix ${ }^{\mathrm{TM}}$; GSK Vaccines, Rixensart, Belgium) was developed for the prevention of RVGE in children using a two-dose regimen [11]. The dosage and administration of Rotarix ${ }^{\mathrm{TM}}$ in Japan is similar to that in other countries; the first dose may be administered as early as 6 weeks of age and it is recommended that it be administered before the age of 14 weeks. There should be an interval of at least 4 weeks between doses, and the vaccine course should be completed by the age of 24 weeks. In Japan, this vaccine has been shown to be efficacious, well-tolerated, and immunogenic in infants aged 6-14 weeks [12]. Rotarix ${ }^{\mathrm{TM}}$ was launched in November 2011 as the first rotavirus vaccine in Japan, with the prevention of RVGE as the indication. In Japan, rotavirus vaccination is privately funded as of the year 2015. In a recent prospective observational study in three pediatric clinics in Shibata City, Niigata Prefecture, a significantly lower occurrence of severe RVGE in children under 3 years of age was observed in three consecutive seasons after the introduction of rotavirus vaccination than in the pre-vaccination 2011 RVGE epidemic season [13, 14].

In Japan, as stipulated in the Pharmaceutical Affairs Law, companies are required to conduct an Early Postmarketing Phase Vigilance (EPPV) for the first 6 months after the launch of a new drug [15]. The occurrence of intussusception after vaccination is particularly well-monitored, since the first licensed rotavirus vaccine (RotaShield $^{\mathrm{TM}}$; Wyeth Laboratories, Marietta, PA, USA) was associated with a risk of intussusception and withdrawn from the US market 9 months after its introduction [16]. An increase in the incidence of intussusception is now also known to occur as a rare adverse event following Rotar$\mathrm{ix}^{\mathrm{TM}}$ and RotaTeq ${ }^{\mathrm{TM}}$ (Merck \& Co., Inc., Whitehouse Station, NJ, USA) rotavirus vaccination [17].

Intussusception is a rare condition, but it is the most common cause of acute intestinal obstruction among infants and young children [18]. If not treated early, intussusception may become a medical emergency and may eventually lead to death [18]. The incidence of intussusception is highly variable by region [19]. In Japan, the background incidence rate of intussusception is one of the highest in the world, with estimates ranging between 143.5 and 191 cases per 100,000 children-years in the first year of life [20-23]. However, most cases can be successfully treated with hydrostatic enema, and less than $10 \%$ of intussusception hospitalizations lead to surgery [23].

A recent observed versus expected analysis of Japanese data based on spontaneous safety reporting has shown a temporal association between the development of intussusception and the receipt of Rotarix ${ }^{\mathrm{TM}}$ within 7 days post dose 1 [24]. These results were consistent with previous observations in large post-marketing safety studies in other regions of the world [25-29]. The WHO has recently recommended the use of Rotarix ${ }^{\mathrm{TM}}$ and RotaTeq ${ }^{\mathrm{TM}}$ in all national immunization programs [30]. Both vaccines continue to be used worldwide, including in countries where a risk of intussusception has been detected (USA, Australia, Mexico, Brazil, Singapore) since the benefits are considered to outweigh the intussusception risk [25, 27, 31-34].

Benefit-risk analyses offer a comparative analysis of the benefits and risks of vaccination. Such analyses are used as a decision-support tool to inform regulatory authorities, clinicians, and parents about the benefit-risk balance of vaccination. We performed a benefit-risk analysis of rotavirus vaccination versus no vaccination to compare the incidence of vaccine-preventable hospitalizations and deaths due to RVGE (benefit) over a period of 5 years, with vaccine-associated hospitalizations and deaths due to intussusception (risk) following the first and second dose of Rotarix $^{\mathrm{TM}}$ in Japan.

\section{Methods}

Data from peer-reviewed clinical and epidemiological publications and Japanese governmental statistics were used to populate the benefit-risk analysis. Data from market surveys (age distribution of children at the first dose of Rotarix ${ }^{\mathrm{TM}}$ and distribution of the delays before administration of the second dose) were also included. The source data were identified, reviewed, and validated by several GSK Vaccines experts in epidemiology and safety (AL, $\mathrm{KH}$, and KS). Data had to be recent, reliable, representative of the general population, and meet the requirement of our case definitions for hospitalized RVGE or intussusception. Source publications were reviewed by comparing overall rates with those from other countries with high-quality data available, including the USA and Australia. Preferences were given to actual Japanese data, providing age-specific RVGE rates pertaining to the age strata under consideration, focusing on severe hospitalized cases of RVGE and intussusception. All parameters included in the benefit-risk analysis and their random distributions are given in Table 1. Benefit-risk estimates were calculated for a large 
Table 1 Model input random variables used for probabilistic uncertainty analysis

\begin{tabular}{|c|c|c|c|}
\hline Input & Median $(95 \% \mathrm{CI})^{\mathrm{a}}$ & Distribution $^{\mathrm{b}}$ & Source \\
\hline \multicolumn{4}{|l|}{ Demography } \\
\hline Age at first dose (months) & $2.7(1.4-4.9)$ & Dirichlet multinomial $^{\mathrm{c}}$ & $\begin{array}{l}\text { JVC Japanese Survey (unpublished } \\
\text { data, see Supplementary Fig. S2) }\end{array}$ \\
\hline $\begin{array}{l}\text { Delay before second dose } \\
\text { (months) }\end{array}$ & $1.7(1.0-4.5)$ & Dirichlet multinomial $^{\mathrm{d}}$ & $\begin{array}{l}\text { JVC Japanese Survey (unpublished } \\
\text { data, see Supplementary Fig. S3) }\end{array}$ \\
\hline \multicolumn{4}{|l|}{ RVGE } \\
\hline $\begin{array}{l}\text { Baseline hospitalization rate due } \\
\text { to } \mathrm{RVGE} / 10^{6} \text { children } \\
\text { aged }<5 \text { years/year }\end{array}$ & $4166(3260-5226)$ & Gamma $(69,16,558)$ & Kamiya et al. [7] \\
\hline $\begin{array}{l}\text { Mortality rate due to RVGE } / 10^{6} \\
\text { children aged }<5 \text { years/year }\end{array}$ & $1.47(1.14-1.86)$ & Gamma $(65,44,034,734)$ & Japanese Statistics [36] \\
\hline $\begin{array}{l}\text { Vaccine efficacy against RVGE } \\
\text { D2 (\%) }\end{array}$ & $91.6(62.4-99.1)$ & $\begin{array}{l}\text { Log-normal on relative risk } \\
\quad(\operatorname{Ln}(1-0.916), 0.767)\end{array}$ & Kawamura et al. [12] \\
\hline $\begin{array}{l}\text { Ratio of vaccine effectiveness } \\
\text { against RVGE after a 1-dose vs. } \\
\text { 2-dose schedule }\end{array}$ & $0.82(0.73-0.88)$ & Beta $(81,19)$ & Payne et al. [37] \\
\hline $\begin{array}{l}\text { Vaccine efficacy against RVGE } \\
\text { D1 }(\%)\end{array}$ & $73.9(50.1-83.7)$ & Empirical $^{\mathrm{e}}$ & Product of the 2 distributions above \\
\hline Compliance of second dose & $0.98(0.95-0.99)$ & Beta $(195,4.2)$ & JVC Japanese Survey (unpublished data) \\
\hline \multicolumn{4}{|l|}{ IS } \\
\hline $\begin{array}{l}\text { Baseline hospitalization rate due } \\
\text { to IS } / 10^{6} \text { infants aged }<1 \text { year/ } \\
\text { year }\end{array}$ & $1571(1308-1868)$ & Gamma $(122,77,436)$ & Noguchi et al. [22] \\
\hline $\begin{array}{l}\text { Mortality rate due to IS } / 10^{6} \\
\text { infants aged }<1 \text { year/year }\end{array}$ & $0.54(0.19-1.18)$ & Gamma $(5,8,639,044)$ & Japanese statistics [36] \\
\hline $\begin{array}{l}\text { IS fatality risk } / 10^{5} \text { IS } \\
\text { hospitalization }\end{array}$ & $34.4(11.8-77.2)$ & Empirical & Derived from 2 distributions above \\
\hline $\begin{array}{l}\text { Relative risk of IS post dose } 1 \\
\text { and post dose } 2\end{array}$ & $\begin{array}{l}\text { D1: } 5.39(3.92-7.40) \\
\text { D2: } 1.81(1.21-2.71)\end{array}$ & $\begin{array}{l}\text { Log-normal } \\
(\operatorname{Ln}(5.39), 0.16) \\
(\operatorname{Ln}(1.81), 0.20)\end{array}$ & Rosillon et al. [17] \\
\hline
\end{tabular}

$C I$ confidence interval, D1 post dose 1, D2 post dose 2, IS intussusception, JVC Japan Vaccine Co., Ltd., Tokyo, Japan, $R V G E$ rotavirus gastroenteritis

${ }^{\text {a }}$ The limits of the $95 \%$ CIs were determined using the 2.5 and $97.5 \%$ percentiles of our simulations implemented and correspond as much as possible with the CI limits published in the source documents

b The approximate distribution parameters provided are gamma (shape, rate), LogNormal (mean, standard deviation), and beta ( $\alpha$, $\beta$ )

c The parameters of the Dirichlet-multinomial are $(12,121,49,11,4)$ for the age at first dose ranging from 1 to 5 months. A day of the month was randomly drawn for each simulation

d The parameters of the Dirichlet-multinomial are $(373,80,22,22,2.4)$ for delays between the two vaccinations ranging from 1 to 5 months. A day of the month was randomly drawn for each simulation

e The distribution of vaccine efficacy D1 is given in Electronic Supplementary Material Fig. S1

number $\left(\sim 10^{6}\right)$ of scenarios generated randomly by selecting a different combination of values drawn from the distribution of the input parameters. Confidence intervals (CIs) around the benefit-risk ratios and differences were calculated based on probabilistic uncertainty analysis and Monte-Carlo simulations [31, 35].

\subsection{Data Used to Support the Benefit Estimate}

The baseline RVGE hospitalization rate was calculated based on estimated means of overall and age-specific hospitalization rates in two cities (Tsu and Ise) of the Mie prefecture over a risk window of 5 years [7]. Mortality rates due to severe RVGE were estimated using the number of RVGE deaths in Japanese children aged $<5$ years and the Japanese birth cohort from 2004 to 2011 [36].

Vaccine efficacy against RVGE was derived from a phase III, randomized, double-blind study, which assessed the efficacy, reactogenicity, safety, and immunogenicity of two doses of Rotarix ${ }^{\mathrm{TM}}$ in Japanese infants aged 6-14 weeks [12]. Because vaccine efficacy post dose 1 was not calculated in this Japanese trial [12], we estimated vaccine efficacy post dose 1 (see Electronic Supplementary Material Fig. S1) using the calculated ratio of vaccine 
effectiveness after one dose to vaccine effectiveness after a two-dose schedule in the USA [37]. Vaccine efficacy was considered constant over the 5-year risk window used for the modeling since an absence of waning of protection has been documented for at least 3 years [38].

The age distribution of children at the first dose of $\operatorname{Rotarix}^{\mathrm{TM}}$ is based on a survey performed among 100 general practitioners, randomly selected from pediatric clinics all over Japan, between 5 and 11 July 2013 (Electronic Supplementary Material Fig. S2). A survey among 500 mothers, randomly selected from Japanese mothers (from all over Japan) who had children under 8 months of age and were registered with a survey company, was performed to provide information on the distribution of the delays before administration of the second dose (Electronic Supplementary Material Fig. S3). Both surveys were conducted via internet questionnaires.

The age at the first dose of vaccination and the delay prior to the second dose of vaccination define the windows where the one-dose and two-dose vaccine efficacy apply and were used to calculate the vaccine preventable fraction of the RVGE baseline rates. The reduction in number of RVGE hospitalizations was calculated for the population of 1 million vaccinees over a period of 5 years, and derived from the baseline hospitalization rate and the vaccinepreventable fraction. The non-preventable fraction was defined as the ratio between the sum of (i) the number of baseline RVGE hospitalizations prior to the first dose of vaccination, (ii) the breakthrough RVGE hospitalizations prior to and after the second dose of vaccination, and (iii) the RVGE hospitalizations occurring due to non-compliance to vaccination, divided by the total number of baseline RVGE hospitalizations over 5 years.

Rotarix $^{\mathrm{TM}}$ efficacy against RVGE hospitalization was assumed to be similar to Rotarix ${ }^{\mathrm{TM}}$ efficacy against RVGE death since nearly all severe RVGE cases in Japan are hospitalized. Therefore, the same RVGE vaccine-preventable fraction for hospitalization was applied to the RVGE deaths.

\subsection{Data Used to Support Risk Estimate}

Baseline age-specific intussusception rates in infants aged $<1$ year were based on a previous retrospective crosssectional study that reviewed the medical charts of all hospitals that provided pediatric beds in Akita Prefecture, Japan, and identified the cases of intussusception that met the Brighton criteria level 1 in these hospitals between January 2001 and December 2010 [22].

The intussusception hospitalization rate following vaccination after the first and the second dose was calculated using the intussusception baseline hospitalization rate at vaccination age multiplied by the relative risk of intussusception reported for each of the two vaccine doses, resulting from a recent meta-analysis across several countries (USA, Australia, Mexico, Brazil) [17]. The increase in the number of intussusception hospitalizations after vaccination was calculated for a population of 1 million vaccinees over a risk window of 7 days post vaccine dose 1 and 2 .

The intussusception fatality risk following hospitalization was calculated as the ratio of the intussusception mortality rate [36] to the intussusception hospitalization rate [22]. The increase in the number of intussusception deaths for the population of 1 million vaccinees over 5 years was calculated as the additional number of intussusception hospitalizations attributed to the vaccine multiplied by the intussusception fatality risk.

\subsection{Benefit Versus Risk Analysis}

The hospitalization benefit-risk comparison was expressed as the ratio of the reduction in the number of severe RVGE hospitalizations attributable to vaccination over 5 years and the increase in the number of intussusception hospitalizations attributable to vaccination for a risk window of 7 days following vaccination, relative to the same cohort of 1 million vaccinees. Similarly, the death benefit-risk comparison was expressed as a ratio of the reduction in the number of RVGE deaths over 5 years and the additional number of intussusception deaths over a risk window of 7 days post-vaccination. The differences between benefits and risks were also estimated and expressed as the difference between the reduction in number of RVGE hospitalizations (or deaths) and the increase in number of intussusception hospitalizations (or deaths).

\subsection{Statistical Methods}

Random distributions were assigned to the key model parameters (Table 1) in order to implement up to $10^{6}$ Monte-Carlo simulations and generate an empirical distribution for the ratio and difference of the benefit and risk estimates. The number of simulation draws was equal to $10^{6}$. All draws were made independently, using a different seed, and considering all distributions as independent. The simulations included age at vaccinations and delays between the two vaccine doses, which can be more easily understood as scenarios (or variations) of the vaccine schedule. We used the wording "scenario" indistinctly for the two aspects of the probabilistic sensitivity analyses. Parameters of random distributions were estimated to approximately reproduce the CI limits reported in publications, using conjugate Bayesian distributions and leastsquares methods. A weighted average of the RVGE hospitalization rates pertaining to the Tsu and Ise hospitals [7] was calculated according to the size of the cohorts in each hospital area. A weighted average of age-specific RVGE or 
intussusception rates was calculated, and their weights were proportional to the duration of the age window they covered. The few $(<0.06 \%)$ negative instances of vaccine efficacy resulting from the simulations were assigned a zero value, since the vaccine is indicated for the prevention of RVGE disease. Regression techniques using the NLIN procedure in $\mathrm{SAS}^{\circledR}$ (SAS Institute, Cary, NC, USA) were applied to calculate the rate as a function of the age of children. The sensitivity of the model for each input parameter was assessed comparing the benefit-risk estimate using mean input values with the estimates using the whole range of plausible input values. The variation around the mean benefit-risk estimation through simulations was related to the percentiles of the key input parameters.

A non-linear regression model was used to fit the baseline RVGE hospitalization rate as a function of child age (Fig. 1a). The RVGE preventable fraction was calculated as the ratio between the post-vaccination area under the curve, accounting for vaccine efficacies after one and two doses, and the area under the curve using baseline rates. Similarly, a non-linear regression model was used to fit the baseline intussusception hospitalization rate as a function of child age (Fig. 1b). The curve provided the mean baseline intussusception incidences over the 7-day risk windows following the first and second dose of vaccination.

The CIs for the benefit-risk ratio were determined using the 2.5 and $97.5 \%$ percentiles of the empirical distribution. Both means and medians were tabulated (Electronic Supplementary Material Table S1). The medians, being robust centrality estimates, and less sensitive to extreme values and skewness of the distribution, are presented in the main body of this paper; at most, half of the simulations provide results strictly less than the median value.

An outline of the benefit-risk model was explored in Microsoft Excel $^{\circledR}$ and specifications were written prior to implementation of the simulations in $\mathrm{SAS}^{\circledR}$ software (version 9.2).

\section{Results}

In the absence of rotavirus vaccination in Japan, we estimate that the annual hospitalization rate for RVGE is 4166 (95\% CI 3260-5226) per 1 million children below 5 years of age (Table 1), bringing this number up to 20,000 in the cohort of 1 million children followed for 5 years, with a peak incidence at around 10 months of age (Fig. 1a). The annual intussusception hospitalization rate is 1571 (95\% CI 1308-1868) per 1 million infants below 1 year of age, with a peak incidence at around 7 months of age (Fig. 1b). The annual mortality rate due to severe RVGE is 1.47 (95\% CI 1.14-1.86) per 1 million children below 5 years of age, while the annual mortality rate due to intussusception is 0.54 (95\% CI 0.19-1.18) per 1 million infants below 1 year of age.

Within a birth cohort of 1 million Japanese children followed for 5 years post-vaccination with two doses of Rotarix $^{\mathrm{TM}}, 17,925$ (95 \% CI 11,715-23,276) RVGE-associated hospitalizations and 6.3 (95\% CI 4.1-8.2) RVGEassociated deaths could be avoided (Table 2; Electronic Supplementary Material Fig. S4). Overall, $86 \%$ (95\% CI 60-95) of hospitalized RVGE cases could be prevented within 5 years following vaccination.

With a fully implemented Rotarix ${ }^{\mathrm{TM}}$ vaccination program in Japan, we estimated that vaccination could potentially cause 50 (95\% CI 7.2-237) intussusception hospitalizations and 0.017 (95\% CI 0.0020-0.097) intussusception associated deaths in the same fully vaccinated cohort (Electronic Supplementary Material Fig. S5), calculated over two risk windows of 7 days following the first and second dose of Rotarix ${ }^{\mathrm{TM}}$. The number of intussusception hospitalizations potentially caused by Rotarix ${ }^{\mathrm{TM}}$ represents a $\sim 3 \%$ increase over the baseline number of intussusception cases (1571) occurring in 1 million infants during their first year of life.

The results of the probabilistic sensitivity analysis of the reduction in number of RVGE hospitalizations (benefit) and the increase in number of intussusception hospitalizations (risk) are presented in Fig. 2 and a ratio between benefit and risk was calculated for each simulation (Electronic Supplementary Material Fig. S6).

The Rotarix ${ }^{\mathrm{TM}}$ benefit-risk ratios for hospitalization and death are 350:1 and 366:1, respectively. This means that for one intussusception hospitalization caused (in every 20,000 vaccinated infants), 350 RVGE hospitalizations will be prevented (Table 2). With a median (mean) vaccine-related intussusception death rate of $0.017(0.025)$ per 1 million vaccinees per year, one death might be reported over a median (mean) period of $\sim 60$ (40) years, while vaccinating the whole Japanese birth cohort ( $\sim 1$ million children/year) over the same period would prevent 366 RVGE-associated deaths. The benefit-risk difference shows that 17,855 hospitalizations and 6.3 deaths could be averted in a birth cohort of 1 million Japanese children followed for 5 years post-vaccination with two doses of Rotarix ${ }^{\mathrm{TM}}$.

The sensitivity analysis summarized in a tornado diagram (Fig. 3a) revealed the increase in the benefit-risk ratio for hospitalization when two doses of Rotarix ${ }^{\mathrm{TM}}$ are administered to children at younger ages $(<2.5$ months of age) because both RVGE and intussusception incidences are age dependent. The second most influential variable is the relative risk of intussusception following the second dose of vaccination. The other variables had a low influence on the benefit-risk ratio (Fig. 3a). A similar sensitivity analysis performed on the benefit-risk difference (Fig. 3b) revealed that the two most influential variables 

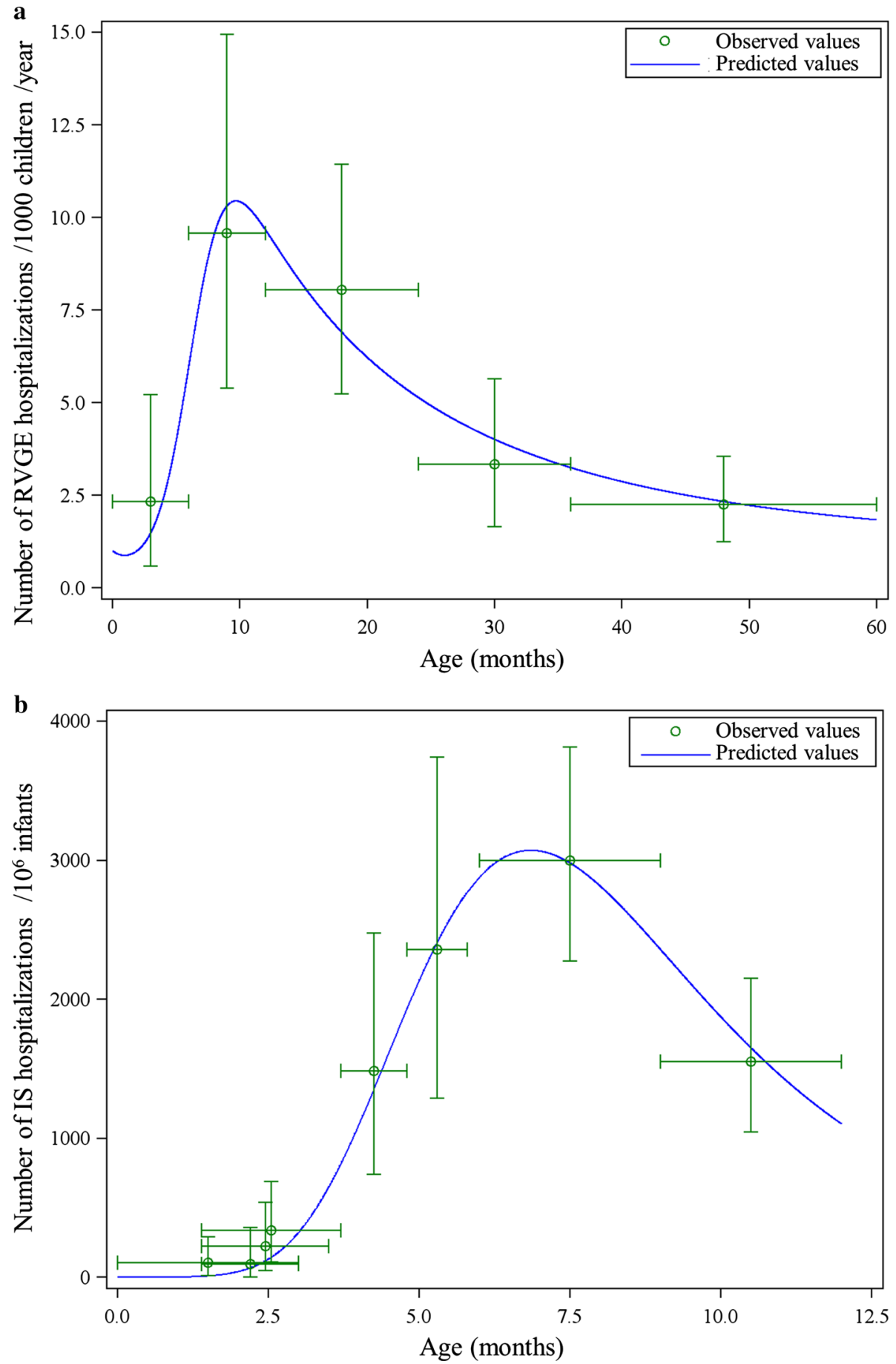

Fig. 1 Interpolation of age-specific rotavirus gastroenteritis hospitalization rates in children $0-60$ months of age (a) and age-specific intussusception hospitalization rates in infants ( $0-12$ months of age) (b). a The observed values represent the rotavirus gastroenteritis hospitalization rate, by age, in two cities (Tsu and Ise) from the Mie Prefecture, Japan, 2003-2007 [7]. Vertical bars define the $95 \%$ confidence interval around mean age-specific rotavirus gastroenteritis rates. Horizontal bars define the age range over which the hospitalization rate was estimated. The coefficients of the fitted curve, $\exp \left(3.16 \times \exp (-0.027 \times\right.$ age $)-3.16 \times \exp \left(-0.043 \times \mathrm{age}^{2}+0.045\right.$ $\times$ age)), were determined by least-squares and contributed to the calculation of the preventable fraction of the rotavirus gastroenteritis rate. b The observed values represent the intussusception hospitalization rate among children $\leq 24$ weeks of age in Akita Prefecture, Japan, between 2001 and 2010 [22]. Vertical bars define the $95 \%$ confidence interval around mean age-specific intussusception rates. Horizontal bars define the age range over which the hospitalization rate was estimated. The coefficients of the fitted curve, $10 \times \exp [9.18 \times \exp (-$ $0.062 \times($ age -1.62$))-9.18 \times \exp (-0.438 \times($ age -1.62$))], \quad$ were determined by least-squares and were used to calculate the mean intussusception rate over a 7-day risk window after each of the two vaccinations. IS intussusception, $R V G E$ rotavirus gastroenteritis 
Table 2 Benefit and risk of vaccination with Rotarix ${ }^{\mathrm{TM}}$ in a birth cohort of 1 million Japanese children followed for a period of 5 years postvaccination

\begin{tabular}{|c|c|c|c|c|c|c|}
\hline \multirow[t]{2}{*}{ Event } & \multicolumn{2}{|l|}{ Baseline incidence } & \multirow{2}{*}{$\begin{array}{l}\text { Benefit } \\
\text { Prevented RVGE }\end{array}$} & \multirow{2}{*}{$\begin{array}{l}\text { Risk } \\
\text { Excess IS }\end{array}$} & \multirow{2}{*}{$\begin{array}{l}\text { B-R ratio } \\
\text { (prevented RVGE/ } \\
\text { excess IS) }\end{array}$} & \multirow{2}{*}{$\begin{array}{l}\text { B-R difference } \\
\text { (prevented RVGE minus } \\
\text { excess IS) }\end{array}$} \\
\hline & $\mathrm{RVGE}^{\mathrm{a}}$ & $\mathrm{IS}^{\mathrm{b}}$ & & & & \\
\hline Hospitalization & $\begin{array}{l}20,829 \\
\quad(16,301-26,129)\end{array}$ & $\begin{array}{l}1571 \\
\quad(1308-1868)\end{array}$ & $\begin{array}{l}17,925 \\
\quad(11,715-23,276)\end{array}$ & $50(7.2-237)$ & $350(69-2510)$ & $17,855(11,643-23,213)$ \\
\hline Death & $7.3(5.7-9.3)$ & $\begin{array}{l}0.54 \\
\quad(0.19-1.18)\end{array}$ & $6.3(4.1-8.2)$ & $\begin{array}{l}0.017 \\
\quad(0.0020-0.097)\end{array}$ & $366(59-3271)$ & $6.3(4.1-8.2)$ \\
\hline
\end{tabular}

Medians and $95 \%$ confidence (credible) intervals are provided in the table. The mean values are given in Electronic Supplementary Material Table S1

$B-R$ benefit-risk, $I S$ intussusception, $R V G E$ rotavirus gastroenteritis

${ }^{a}$ Number of RVGE-related hospitalizations and deaths per 1 million children followed from birth to 5 years of age, calculated from the annual hospitalization rate for RVGE (Table 1)

b Number of IS-related hospitalizations and deaths estimated per 1 million infants followed from birth to 1 year of age

${ }^{c}$ Number of vaccine-prevented RVGE-related hospitalizations and deaths per 1 million vaccinated children followed from birth to 5 years of age

${ }^{\mathrm{d}}$ Overall number of IS-related events caused during two risk windows of 7 days post-dose 1 and post dose 2 of Rotarix ${ }^{\mathrm{TM}}$

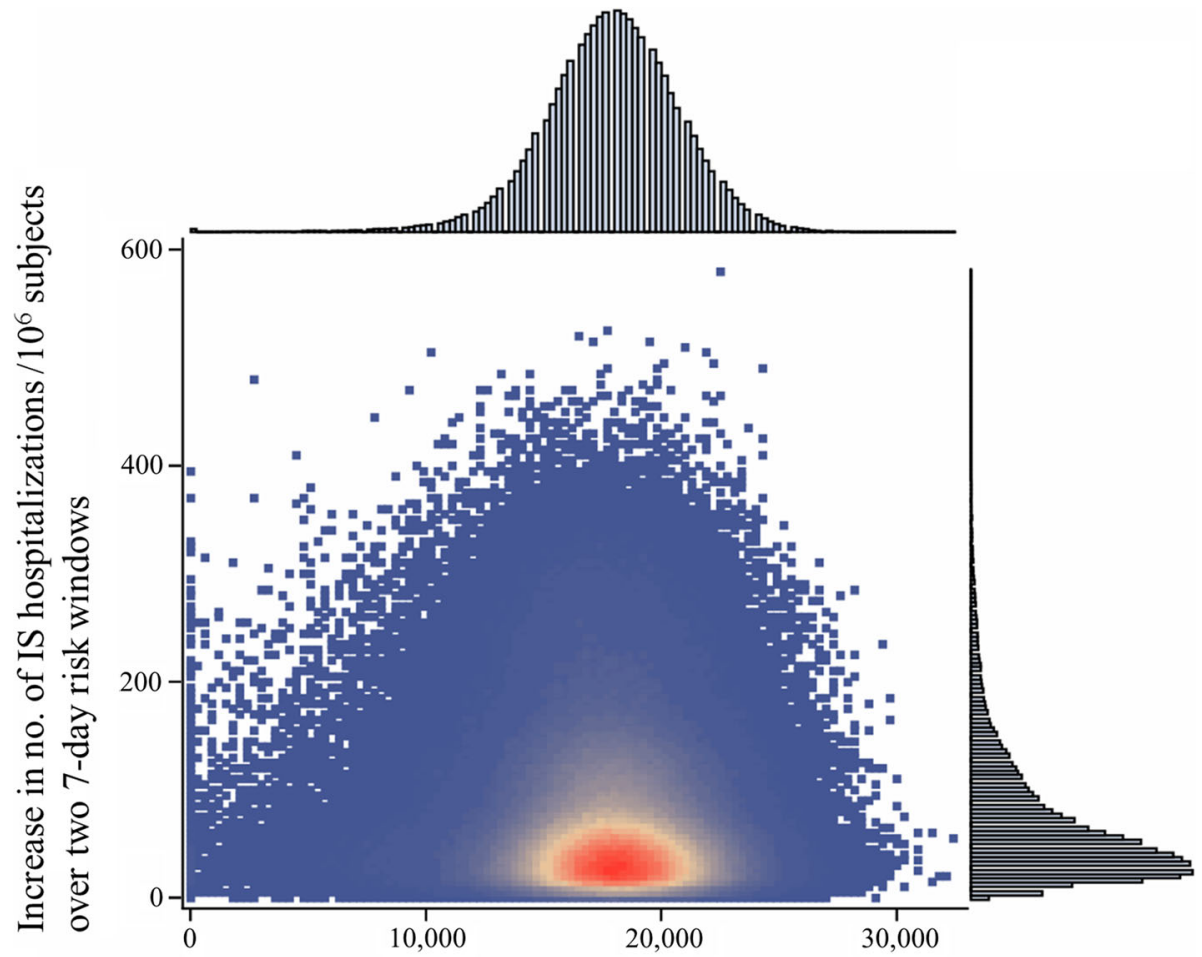

Reduction in no. of RVGE hospitalizations $/ 10^{6}$ subjects over 5 years

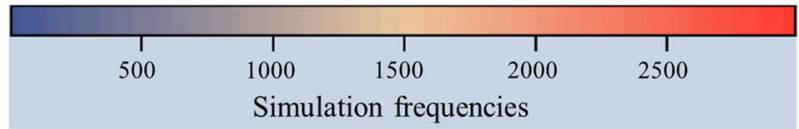

Fig. 2 Two-dimensional plot of the overall reduction in numbers of rotavirus gastroenteritis hospitalizations over a 5-year risk window ( $x$ axis) and the increase in numbers of intussusception hospitalizations post-vaccination over two 7-day risk windows (y-axis) for a cohort of 1 million vaccinated Japanese children. Each point represents the joint calculations of benefits and risks under a specific scenario selected at random from each of the random distributions of the input parameters. The results presenting the highest frequencies across the $10^{6}$ simulations are red. The plot illustrates the dominance of the hospitalization benefits in comparison to the hospitalization risks under all scenarios. The distribution of the reduction in the number of rotavirus gastroenteritis hospitalizations over a 5-year risk window in 1 million vaccinees, averaged across all intussusception results, is presented on the upper $x$-axis. The distribution of the increase in numbers of intussusception hospitalizations post-vaccination over two 7-day risk windows in 1 million vaccinees, averaged across all rotavirus gastroenteritis results, is presented on the right y-axis. IS intussusception, $R V G E$ rotavirus gastroenteritis 
Fig. 3 Sensitivity analyses assessing the impact of the variability of model parameters on the benefit-risk ratio (a) and benefit-risk difference (b) for hospitalization. The $x$-axis of the tornado diagrams shows the variations of the benefit-risk ratio around its mean value as a result of variations of the main input parameters. The left and right limits of each horizontal bar indicate the change in benefit-risk ratio calculated for the 1 and $99 \%$ percentile values of the input parameter mentioned. Other symbols indicate the benefit-risk variations expected for those percentiles of the input parameter. $B R$ benefit-risk, $D I$ dose 1, D2 dose 2, hosp. hospitalization, $I S$ intussusception, Max maximum, Min minimum, $Q 1$ first quartile, $Q 3$ third quartile, $R R$ relative risk, $R V G E$ rotavirus gastroenteritis, $V E$ vaccine efficacy

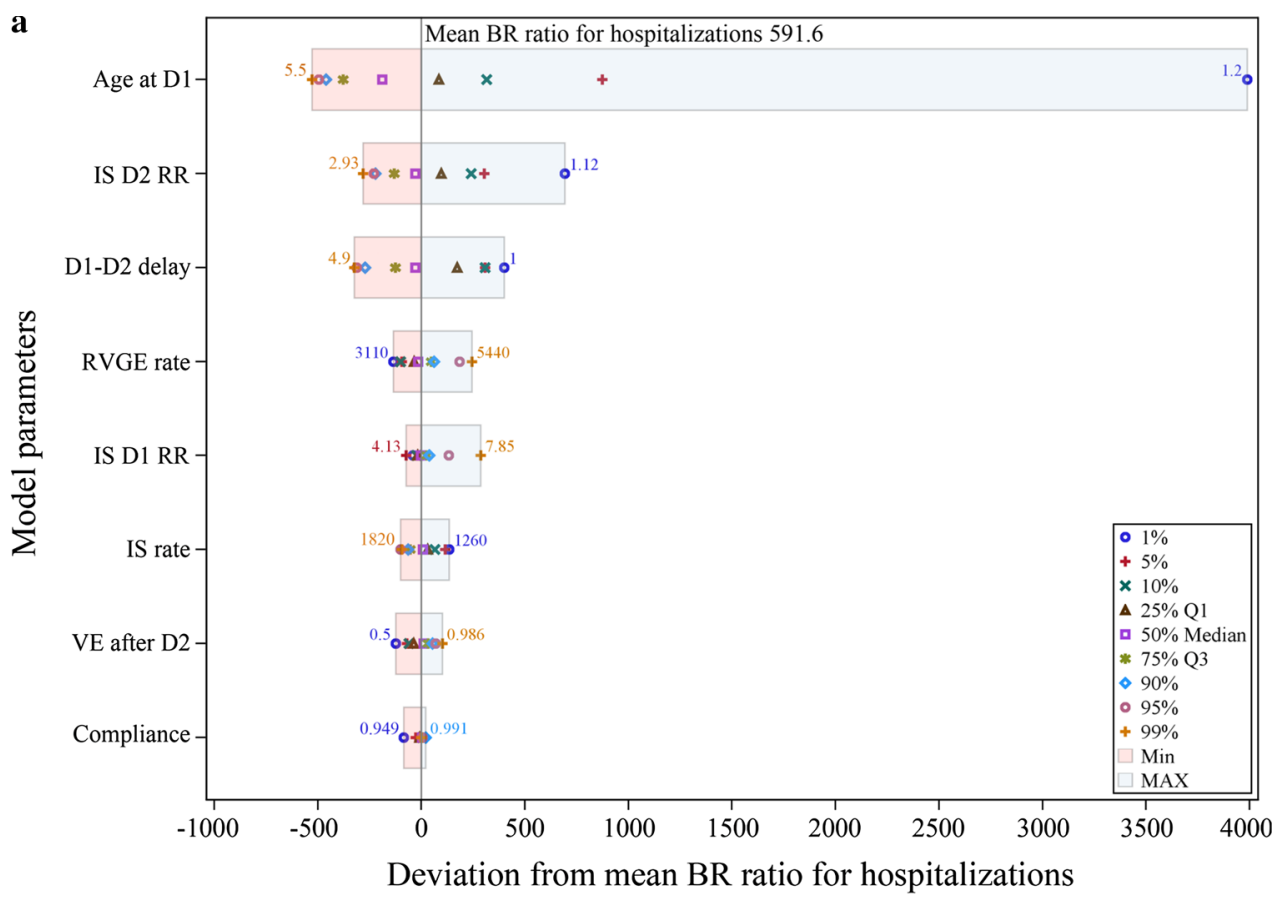

b

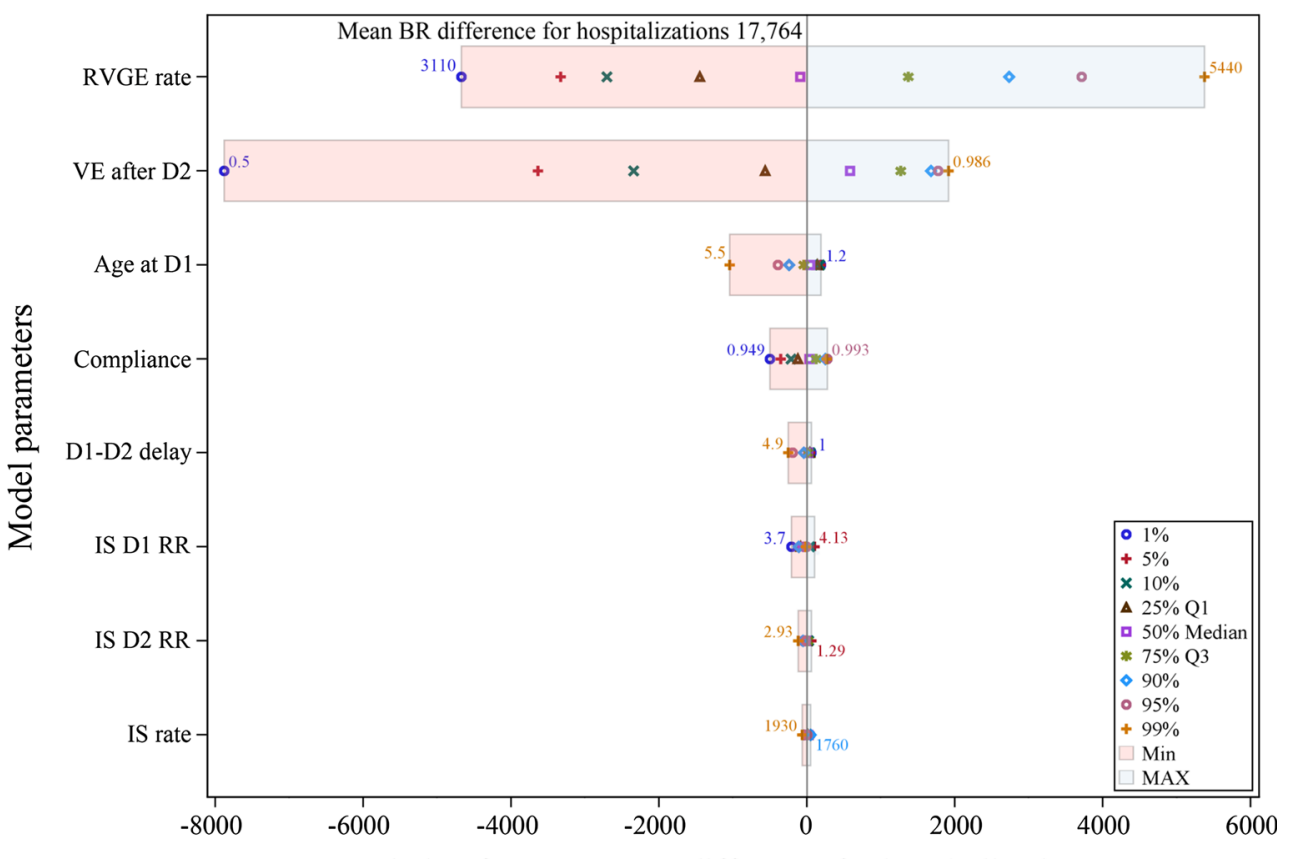

were the RVGE hospitalization rate and the vaccine efficacy after the second dose of vaccination.

\section{Discussion}

The present analysis was carried out to compare the benefit (RVGE reduction) and risk (intussusception) associated with Rotarix $^{\mathrm{TM}}$ vaccination in Japan. For a Japanese birth cohort of 1 million children vaccinated with two doses of Rotarix $^{\mathrm{TM}}$ and followed for 5 years, a reduction of 17,925 (86\%) RVGE-associated hospitalizations and 6.3 RVGEassociated deaths, and a potential additional 50 intussusception-associated hospitalizations, which would represent a $3 \%$ increase from background incidence numbers within the first year after introduction of vaccination, and 0.017 intussusception-associated deaths are predicted due to vaccination. This suggests that about 350 RVGE- 
associated hospitalizations and 366 RVGE-associated deaths would be prevented for each intussusception hospitalization and death caused, respectively.

Overall, the benefit-risk ratio for Japan is favorable and comparable to results from other studies performed in other regions of the world (Table 3) [25, 27, 31, 32, 39]. Differences in the results between studies can be explained by differences in the epidemiology of RVGE and intussusception between countries and by the spread of the range of input values.

In Japan, the background incidence of intussusception is one of the highest in the world [20-23]. The absolute number of cases predicted to be possibly caused by the vaccination is relatively high (50 extra hospitalizations per 1 million infants in the immediate post-vaccination period). The relative increase from baseline is expected to be about $3 \%$. Assuming the same vaccine efficacy within the age range considered, our sensitivity analyses show that timely administration of Rotarix ${ }^{\mathrm{TM}}$ can improve the hospitalization benefit-risk ratio. This is due to a lower intussusception background incidence at lower ages [22]. Moreover, timely vaccination would lead to earlier prevention of RVGE in infants, for whom the RVGE burden is high [10].

On the other hand, the annual mortality rates due to severe RVGE and intussusception are very low in Japan when compared with other countries, since most RVGE and intussusception cases are hospitalized and well-managed. Although the benefit-risk ratio for death in Japan (366:1) is comparable with other countries [25, 31], one intussusception death caused by vaccination would only be expected within a median (mean) period of 60 (40) years. Moreover, our benefit-risk difference estimates of approximately 18,000 hospitalizations averted in a birth cohort of 1 million Japanese children followed for 5 years post-vaccination suggest an important reduction in the medical and economic burden of RVGE in Japan [40].

\subsection{Sensitivity Analyses}

The sensitivity analyses on the benefit-risk ratio reflect the impact of uncertainties on the ratio between the number of hospitalizations prevented and the number of hospitalizations caused. The sensitivity analyses on the benefit-risk difference reflect the impact of uncertainties on the absolute number of hospitalizations prevented (important from a public health perspective). The most influential parameters are different for ratio and difference. The benefit-risk ratio changes significantly when the denominator varies, which explains that most influential parameters are the ones that affect the risks (excess intussusception). The number of RVGE hospitalizations prevented is very large compared with the number of intussusception hospitalizations caused, and the difference is very close to the number of RVGE hospitalizations prevented. Therefore, the most influential parameters in this case are the ones that mostly affect the benefits (RVGE reduction).

Our results show that the benefit-risk ratio would increase from its mean value of $\sim 592$ up to $\sim 4500$ should the age at the first vaccination decrease from its mean value of 2.8 months to its first percentile value of 1.2 months. The benefit-risk ratio decreases but remains slightly above unity even if the age at first vaccination increases towards 5.5 months. The increase in the intussusception relative risk following the second dose from its mean value of 1.8

Table 3 Benefit-risk estimates in other regions of the world based on one vaccinated birth cohort followed to 5 years of age

\begin{tabular}{|c|c|c|c|c|c|c|}
\hline Region & Birth cohort & Event & Prevented RVGE & Caused IS & B-R ratio (RVGE/IS) & References \\
\hline \multirow[t]{2}{*}{ Brazil } & \multirow[t]{2}{*}{$3,068,249$} & Hospitalizations & 69,572 & 55 & $1265^{\mathrm{a}}$ & \multirow[t]{2}{*}{ [25] } \\
\hline & & Deaths & 640 & 3 & $213^{\mathrm{a}}$ & \\
\hline \multirow[t]{2}{*}{ Mexico } & \multirow[t]{2}{*}{$2,414,329$} & Hospitalizations & 11,551 & 41 & $282^{\mathrm{a}}$ & \multirow[t]{2}{*}[25]{} \\
\hline & & Deaths & 663 & 2 & $331^{\mathrm{a}}$ & \\
\hline \multirow[t]{2}{*}{ Australia } & \multirow[t]{2}{*}{290,446} & Hospitalizations & 6528 & 14 & $466^{\mathrm{a}}$ & \multirow[t]{2}{*}{ [27] } \\
\hline & & Deaths & NR & NR & NR & \\
\hline \multirow[t]{2}{*}{ USA } & \multirow[t]{2}{*}{$4,261,494$} & Hospitalizations & 53,444 & 45 & 1093 & \multirow[t]{2}{*}{ [32] } \\
\hline & & Deaths & 14 & 0.2 & 71 & \\
\hline \multirow[t]{2}{*}{ Latin America } & \multirow[t]{2}{*}{$9,588,000$} & Hospitalizations & 144,746 & 172 & 841 & \multirow[t]{2}{*}{ [31] } \\
\hline & & Deaths & 4124 & 10 & 395 & \\
\hline \multirow[t]{2}{*}{ England } & \multirow[t]{2}{*}{656,457} & Hospitalizations & 13,276 & 35 & 375 & \multirow[t]{2}{*}{ [39] } \\
\hline & & Deaths & 2.86 & 0.03 & 88 & \\
\hline \multirow[t]{2}{*}{ Japan } & \multirow[t]{2}{*}{$1,018,400$} & Hospitalizations & 17,925 & 50 & 350 & \multirow[t]{2}{*}{ This study } \\
\hline & & Deaths & 6.3 & 0.017 & 366 & \\
\hline
\end{tabular}

$B-R$ benefit-risk, $I S$ intussusception, $N R$ not reported, $R V G E$ rotavirus gastroenteritis

${ }^{\text {a }}$ Calculated using data from the original publications 
up to its first percentile value of 2.93 also decreases the benefit-risk ratio but remains largely above unity. The benefit-risk difference remains considerably above zero irrespective of the input parameter considered in the sensitivity analysis. The benefit-risk difference reduces at most by $\sim 8000$ units from its mean value of 17,764 when the vaccine efficacy decreases from its mean value of $91.6 \%$ to its first percentile value of $50 \%$. All of these results illustrate the robustness of our conclusions of a favorable benefit-risk balance for Rotarix ${ }^{\mathrm{TM}}$ in Japan.

\subsection{Limitations}

There are several limitations in this analysis. First, data on incidence of RVGE and intussusception are limited in Japan, and, therefore, we had to rely on a limited number of available publications. The number of deaths due to RVGE and intussusception in previous years has been obtained from Japanese governmental statistics (Statistics Bureau, Ministry of Internal Affairs and Communications) [36], but it is not known if this represents the true mortality picture. We estimated the intussusception fatality risk to be 0.034 (95\% CI 0.012-0.077) per 100 hospitalizations based on national statistics (five intussusception deaths in 8.6 million infants aged $<1$ year) and the hospitalization rate (122 intussusception hospitalizations over 77,500 person-years) given by Noguchi et al. [22], assuming that all intussusception cases are hospitalized. Another recent paper estimated the intussusception fatality risk to be 0.08 (95\% CI 0.01-0.30) per 100 hospitalizations [23], but this was based on only two deaths in children aged $>1$ year and no deaths in infants aged $<1$ year out of 2427 children $<18$ years of age. Importantly, the calculated benefit-risk ratio remains considerably larger than unity even if the intussusception fatality risk is higher than assumed; therefore, these discrepancies would still leave a highly favorable benefit-risk balance for the Rotarix ${ }^{\mathrm{TM}}$ vaccine.

Data on timing of administration of the rotavirus vaccine doses is critical for the benefit-risk modeling, given the substantial increase in baseline intussusception rates by week of age in the first few months of life. Since no population-based statistics were available in Japan at the time of the study, we have conducted surveys among doctors and mothers to capture this information. Another aspect is that we have been only able to estimate the risk for hospitalized intussusception and not for outpatient visits as it seems only a small proportion of such cases are handled by outpatients facilities in Japan [20]. However, since the majority $(96 \%)$ of intussusception cases are hospitalized [20], underestimating the excess numbers of intussusception due to vaccination is unlikely. Since Rotarix ${ }^{\mathrm{TM}}$ has only been recently introduced in Japan, the reduction in RVGE-associated hospitalization is based on vaccine efficacy documented in clinical trials rather than vaccine effectiveness, and the percentage reduction in vaccine efficacy after the first dose was estimated based on the calculated ratio between vaccine effectiveness post dose 1 and post dose 2 from the USA [37]. Sustained protection for $\operatorname{Rotarix}^{\mathrm{TM}}$ has been documented for 3 years [38]; however, in our modeling we assumed that it would be maintained over 5 years (the usual RVGE risk window considered in Fig. 1) and that vaccination should prevent the majority of RVGE hospitalizations and deaths within this period.

The risk of intussusception beyond the 7-day post-vaccination period was not considered in the present model. This is due to the analysis being based on a recent metaanalysis of that risk over several studies [17]. The metaanalysis is limited to risk estimates over the 7-day period post-vaccination, mainly due to between-study differences in risk estimates for risk periods after 7 days [25-29] and the lack of evidence for a risk increase after 7 days from a number of these studies [26, 28], as mentioned in Rosillon et al. [17]. However, even if an estimate of risk after 7 days was included, the resulting benefit-risk ratio in Japan would still remain very high and the benefit-risk balance would be highly favorable. To illustrate this, we performed a sensitivity analysis in which we extended the intussusception-related events risk windows from 7 to 21 days while keeping the original input parameters of the model constant. The analysis results of this scenario suggest that about 93 RVGE-associated hospitalizations and 97 RVGEassociated deaths would be prevented for each intussusception hospitalization and death caused, respectively (Electronic Supplementary Material Table S2).

\section{Conclusions}

The benefit-risk analysis is a tool that would help Japanese decision-makers to perform a side-by-side comparison of the benefit and risk of rotavirus vaccination in Japan. Our modeling confirmed that the benefit-risk balance for Rotarix $^{\mathrm{TM}}$ is favorable in Japan. From a public health perspective, this means that the numbers of RVGE hospitalizations and deaths prevented by vaccination are greater than those potentially caused by intussusception.

Acknowledgments The authors would like to thank Naveen Karkada (GSK Vaccines) for his scientific contribution and programing support, Vasile Coman (XPE Pharma and Science) for medical writing assistance, and Roeland Van Kerckhoven (Consultant for Keyrus Biopharma) for editorial assistance and public coordination on behalf of GSK Vaccines.

Author contributions All named authors have contributed to the design/acquisition of data or analysis and interpretation of data. They have provided substantial intellectual and scientific input in the 
development of this manuscript. All authors were involved in critically reviewing the content and revising the manuscript.

\section{Compliance with Ethical Standards}

Funding GlaxoSmithKline Biologicals SA was the funding source and was involved in all stages of the study conduct and analysis. GlaxoSmithKline Biologicals SA also funded all costs associated with the development and the publishing of the present manuscript.

Conflicts of interest Edouard Ledent, Alfons Lieftucht, Hubert Buyse, and Katsiaryna Holl are employed by the GSK group of companies. Keiji Sugiyama is employed by Japan Vaccine Co., Ltd., Tokyo, Japan, an affiliate company of the GSK group of companies. Michael Mckenna was a former employee of the GSK group of companies but is currently employed by Otsuka Europe Development and Commercialisation Ltd. Alfons Lieftucht, Hubert Buyse, and Katsiaryna Holl report ownership of stock options and shares from the GSK group of companies.

Trademarks Rotarix $^{\mathrm{TM}}$ is a trademark of the GSK Group of companies. RotaShield ${ }^{\mathrm{TM}}$ is a trademark of Wyeth-Lederle Vaccines. RotaTeq $^{\mathrm{TM}}$ is a trademark of Merck \& Co., Inc.

Open Access This article is distributed under the terms of the Creative Commons Attribution-NonCommercial 4.0 International License (http://creativecommons.org/licenses/by-nc/4.0/), which permits any noncommercial use, distribution, and reproduction in any medium, provided you give appropriate credit to the original author(s) and the source, provide a link to the Creative Commons license, and indicate if changes were made.

\section{References}

1. Parashar UD, Hummelman EG, Bresee JS, Miller MA, Glass RI. Global illness and deaths caused by rotavirus disease in children. Emerg Infect Dis. 2003;9(5):565-72.

2. Tate JE, Burton AH, Boschi-Pinto C, Steele AD, Duque J, Parashar UD. 2008 estimate of worldwide rotavirus-associated mortality in children younger than 5 years before the introduction of universal rotavirus vaccination programmes: a systematic review and meta-analysis. Lancet Infect Dis. 2012;12(2):136-41. doi:10.1016/s1473-3099(11)70253-5.

3. Kawai K, O’Brien MA, Goveia MG, Mast TC, El Khoury AC. Burden of rotavirus gastroenteritis and distribution of rotavirus strains in Asia: a systematic review. Vaccine. 2012;30(7):1244-54. doi:10.1016/j.vaccine.2011.12.092.

4. Podewils LJ, Antil L, Hummelman E, Bresee J, Parashar UD, Rheingans R. Projected cost-effectiveness of rotavirus vaccination for children in Asia. J Infect Dis. 2005;192(Suppl 1):S133-45. doi:10.1086/431513.

5. Yokoo M, Arisawa K, Nakagomi O. Estimation of annual incidence, age-specific incidence rate, and cumulative risk of rotavirus gastroenteritis among children in Japan. Jpn J Infect Dis. 2004;57(4):166-71.

6. Nakagomi T, Nakagomi O, Takahashi Y, Enoki M, Suzuki T, Kilgore PE. Incidence and burden of rotavirus gastroenteritis in Japan, as estimated from a prospective sentinel hospital study. J Infect Dis. 2005;192(Suppl 1):S106-10. doi:10.1086/431503.

7. Kamiya H, Nakano T, Inoue M, Kamiya H, Abd TT, Patel M, et al. A retrospective evaluation of hospitalizations for acute gastroenteritis at 2 sentinel hospitals in central Japan to estimate the health burden of rotavirus. J Infect Dis. 2009;200(Suppl 1):S140-6. doi:10.1086/605028.

8. Ito H, Otabe O, Katsumi Y, Matsui F, Kidowaki S, Mibayashi A, et al. The incidence and direct medical cost of hospitalization due to rotavirus gastroenteritis in Kyoto, Japan, as estimated from a retrospective hospital study. Vaccine. 2011;29(44):7807-10. doi:10.1016/j.vaccine.2011.07.105.

9. Nakagomi T, Kato K, Tsutsumi H, Nakagomi O. The burden of rotavirus gastroenteritis among Japanese children during its peak months: an internet survey. Jpn J Infect Dis. 2013;66(4):269-75.

10. Tajiri H, Takeuchi Y, Takano T, Ohura T, Inui A, Yamamoto K, et al. The burden of rotavirus gastroenteritis and hospital-acquired rotavirus gastroenteritis among children aged less than 6 years in Japan: a retrospective, multicenter epidemiological survey. BMC Pediatr. 2013;13:83. doi:10.1186/1471-2431-13-83.

11. Buyse H, Vinals C, Karkada N, Han HH. The human rotavirus vaccine Rotarix in infants: an integrated analysis of safety and reactogenicity. Hum Vaccin Immunother. 2014;10(1):19-24. doi:10.4161/hv.26476.

12. Kawamura N, Tokoeda Y, Oshima M, Okahata H, Tsutsumi H, Van Doorn LJ, et al. Efficacy, safety and immunogenicity of RIX4414 in Japanese infants during the first two years of life. Vaccine. 2011;29(37):6335-41. doi:10.1016/j.vaccine.2011.05. 017.

13. Oishi T, Taguchi T, Nakano T, Sudo S, Kuwajima H. The occurrence of severe rotavirus gastroenteritis in children under 3 years of age before and after the introduction of rotavirus vaccine: a prospective observational study in three pediatric clinics in Shibata City, Niigata Prefecture, Japan. Jpn J Infect Dis. 2014;67(4):304-6.

14. Oishi T, Tsukano S, Nakano T, Sudo S, Kuwajima H, For the Shibata RVGE Study Group. Impact of rotavirus vaccination in severe rotavirus gastroenteritis outpatient visits at three pediatric primary care clinics in Shibata city, Niigata prefecture, Japan. Open J Pediatr. 2014;04:291-9. doi:10.4236/ojped. 2014.44040.

15. Biswas P. Pharmacovigilance in Asia. J Pharmacol Pharmacother. 2013;4(Suppl 1):S7-19. doi:10.4103/0976-500x.120941.

16. Centers for Disease Control and Prevention (CDC). Withdrawal of rotavirus vaccine recommendation. MMWR Morb Mortal Wkly Rep. 1999;48(43):1007.

17. Rosillon D, Buyse H, Friedland LR, Ng SP, Velazquez FR, Breuer T. Risk of intussusception after rotavirus vaccination: meta-analysis of postlicensure studies. Pediatr Infect Dis J. 2015;34(7):763-8. doi:10.1097/inf.0000000000000715.

18. WHO. Acute intussusception in infants and children. Incidence, clinical presentation and management: a global perspective. 2002. http://vaccine-safety-training.org/tl_files/vs/pdf/acuteintussusception-infants-children.pdf. Accessed 14 Jan 2015.

19. Jiang J, Jiang B, Parashar U, Nguyen T, Bines J, Patel MM. Childhood intussusception: a literature review. PLoS One. 2013;8(7):e68482. doi:10.1371/journal.pone.0068482.

20. Miura M, Sato K, Muto H, Gopala K, Holl K. Intussusception in Japanese infants: analysis of health insurance claims database. Open J Pediatr. 2013;03(04):311-6. doi:10.4236/ojped.2013.34056.

21. Nakagomi T, Takahashi Y, Arisawa K, Nakagomi O. A high incidence of intussusception in Japan as studied in a sentinel hospital over a 25-year period (1978-2002). Epidemiol Infect. 2006;134(1):57-61. doi:10.1017/s0950268805004644.

22. Noguchi A, Nakagomi T, Kimura S, Takahashi Y, Matsuno K, Koizumi $\mathrm{H}$, et al. Incidence of intussusception as studied from a hospital-based retrospective survey over a 10-year period (2001-2010) in Akita Prefecture, Japan. Jpn J Infect Dis. 2012;65(4):301-5. doi:10.7883/yoken.65.301.

23. Takeuchi M, Osamura T, Yasunaga H, Horiguchi H, Hashimoto $\mathrm{H}$, Matsuda S. Intussusception among Japanese children: an 
epidemiologic study using an administrative database. BMC Pediatr. 2012;12:36. doi:10.1186/1471-2431-12-36.

24. Bauchau V, Van Holle L, Mahaux O, Holl K, Sugiyama K, Buyse H. Post-marketing monitoring of intussusception after rotavirus vaccination in Japan. Pharmacoepidemiol Drug Saf. 2015;24(7):765-70. doi:10.1002/pds.3800.

25. Patel MM, Lopez-Collada VR, Bulhoes MM, De Oliveira LH, Bautista Marquez A, Flannery B, et al. Intussusception risk and health benefits of rotavirus vaccination in Mexico and Brazil. N Engl J Med. 2011;364(24):2283-92. doi:10.1056/NEJMoa1012952.

26. Velazquez FR, Colindres RE, Grajales C, Hernandez MT, Mercadillo MG, Torres FJ, et al. Postmarketing surveillance of intussusception following mass introduction of the attenuated human rotavirus vaccine in Mexico. Pediatr Infect Dis J. 2012;31(7):736-44. doi:10.1097/INF.0b013e318253add3.

27. Carlin JB, Macartney KK, Lee KJ, Quinn HE, Buttery J, Lopert $\mathrm{R}$, et al. intussusception risk and disease prevention associated with rotavirus vaccines in Australia's national immunization program. Clin Infect Dis. 2013;57(10):1427-34. doi:10.1093/cid/ cit520.

28. Yih WK, Lieu TA, Kulldorff M, Martin D, McMahill-Walraven $\mathrm{CN}$, Platt $\mathrm{R}$, et al. Intussusception risk after rotavirus vaccination in U.S. infants. N Engl J Med. 2014;370(6):503-12. doi:10.1056/ NEJMoa1303164.

29. Weintraub ES, Baggs J, Duffy J, Vellozzi C, Belongia EA, Irving $\mathrm{S}$, et al. Risk of intussusception after monovalent rotavirus vaccination. N Engl J Med. 2014;370(6):513-9. doi:10.1056/ NEJMoa1311738.

30. Rotavirus vaccines. WHO position paper-January 2013. Wkly Epidemiol Rec. 2013;88(5):49-64.

31. Desai R, Parashar UD, Lopman B, de Oliveira LH, Clark AD, Sanderson CF, et al. Potential intussusception risk versus health benefits from rotavirus vaccination in Latin America. Clin Infect Dis. 2012;54(10):1397-405. doi:10.1093/cid/cis191.
32. Desai R, Cortese MM, Meltzer MI, Shankar M, Tate JE, Yen C, et al. Potential intussusception risk versus benefits of rotavirus vaccination in the United States. Pediatr Infect Dis J. 2013;32(1):1-7. doi:10.1097/INF.0b013e318270362c.

33. Rha B, Tate JE, Weintraub E, Haber P, Yen C, Patel M, et al. Intussusception following rotavirus vaccination: an updated review of the available evidence. Expert Rev Vaccines. 2014;13(11):1339-48. doi:10.1586/14760584.2014.942223.

34. Yung CF, Chan SP, Soh S, Tan A, Thoon KC. Intussusception and monovalent rotavirus vaccination in Singapore: self-controlled case series and risk-benefit study. J Pediatr. 2015;167(1):163-8 e1. doi:10.1016/j.jpeds.2015.03.038.

35. Doubilet P, Begg CB, Weinstein MC, Braun P, McNeil BJ. Probabilistic sensitivity analysis using Monte Carlo simulation. A practical approach. Med Decis Mak. 1985;5(2):157-77.

36. e-Stat. Portal site of official statistics of Japan. http://www.e-stat. go.jp/SG1/estat/eStatTopPortalE.do. Accessed 14 Jan 2015.

37. Payne DC, Boom JA, Staat MA, Edwards KM, Szilagyi PG, Klein EJ, et al. Effectiveness of pentavalent and monovalent rotavirus vaccines in concurrent use among US children $<5$ years of age, 2009-2011. Clin Infect Dis. 2013;57(1):13-20. doi:10. 1093/cid/cit164.

38. Phua KB, Lim FS, Lau YL, Nelson EA, Huang LM, Quak SH, et al. Rotavirus vaccine RIX4414 efficacy sustained during the third year of life: a randomized clinical trial in an Asian population. Vaccine. 2012;30(30):4552-7. doi:10.1016/j.vaccine. 2012.03.030.

39. Clark A, Jit M, Andrews N, Atchison C, Edmunds WJ, Sanderson C. Evaluating the potential risks and benefits of infant rotavirus vaccination in England. Vaccine. 2014;32(29):3604-10. doi:10. 1016/j.vaccine.2014.04.082.

40. Sato T, Nakagomi T, Nakagomi O. Cost-effectiveness analysis of a universal rotavirus immunization program in Japan. Jpn J Infect Dis. 2011;64(4):277-83. 